\title{
Celecoxib suppresses cutaneous squamous-cell carcinoma cell migration via inhibition of SDFI-induced endocytosis of CXCR4
}

This article was published in the following Dove Press journal:

OncoTargets and Therapy

\author{
Ting Gongl,* \\ Yan $\mathrm{Yu}^{2, *}$ \\ Bo Yang ${ }^{3}$ \\ Min $\operatorname{Lin}^{4}$ \\ Jin-Wen Huang ${ }^{4}$ \\ Bo Cheng ${ }^{4}$ \\ Chao $\mathrm{ji}^{4}$
}

'Academy of Integrative Medicine, Fujian University of Traditional

Chinese Medicine, Fuzhou, Fujian

350I22, China; ${ }^{2}$ Department of

Dermatology, First Hospital of Jilin

University, Changchun, Jilin I3002 I,

China; ${ }^{3}$ Department of Dermatology,

Longhua Hospital, Shanghai University

of Traditional Chinese Medicine,

Shanghai 200032, China; ${ }^{4}$ Department

of Dermatology, First Affiliated

Hospital of Fujian Medical University,

Fuzhou, Fujian 350005, China

*These authors contributed equally to this work
Correspondence: Chao Ji; Bo Cheng Department of Dermatology, First Affiliated Hospital of Fujian Medical University, 20 Chazhong Road, Fuzhou, Fujian 350005, China

Email surpassing.ji@gmail.com; dermavvip@।63.com
Background: Cutaneous squamous cell carcinoma (CSCC), the main type of non-melanoma skin cancer (NMSC), contributes to $20-30 \%$ of the overall number of NMSC cases. Some CSCCs are observed to have metastatic potential induced by solar ultra violet (UV) radiation. Celecoxib, a nonsteroidal anti-inflammatory drug, has been largely associated with prevention of many cancer types. However, the relationship between celecoxib and CSCC cell migration has yet to be determined.

Methods: To determine the association between celecoxib and CSCC, we performed a series of studies in human samples and in vitro models to assess the influence of celecoxib in CSCC cell migration.

Results: In the present study, we found that celecoxib suppresses CSCC cell migration via inhibition of SDF1-induced endocytosis of CXCR4. In addition, ERK/AKT signaling pathways were found to play a key role in this biological process.

Conclusion: Our study provides promising evidence that celecoxib could serve as a potential preventative agent for the metastasis of CSCC cells.

Keywords: celecoxib, SDF1, cell migration, CXCR4, ERK-Akt pathway

\section{Introduction}

Nonmelanoma skin cancer (NMSC) is the most prevalent human cancer and affects more than 3 million people worldwide. Cutaneous squamous-cell carcinoma (CSCC), the main type of NMSC, contributes to $20 \%-30 \%$ of the overall number of NMSC cases. Previous studies have shown that incidence of CSCC is increasing by $10 \%-12 \%$ per year around the world. ${ }^{1}$ A retrospective analysis has reported that about $4 \%$ of CSCC cases have poor prognosis, due to metastasis and local recurrence. ${ }^{2}$ It has been well established that there is a direct correlation between solar ultraviolet (UV) radiation and the metastasis of CSCC. ${ }^{3}$ The increased incidence and morbidity rates of CSCC have generated great interest in conducting further research on the relationship between UV radiation and CSCC metastasis.

SDF1, also known as CXCL12, is a member of the chemokine subfamily and a specific ligand for CXCR4 and CXCR7. ${ }^{4}$ It is known that SDF1 binds to CXCR4 and regulates directional invasion of many types of cancer cells to certain organs, such as the lymph nodes, lungs, liver, and bone marrow, all of which express high levels of SDF1. Constitutive endocytosis is implicated in the regulation of CXCR4 membrane expression and is also associated with cell migration. ${ }^{5,6}$ Furthermore, deletion of the carboxyl terminal domain of CXCR4 abrogates SDF1-induced endocytosis. ${ }^{7}$ Therefore, the SDF1-CXCR4 axis is critical in the metastasis of various types of tumor cells. hereby accept the Terms. Non-commercial uses of the work are permitted without any further permission from Dove Medical Press Limited, provided the work is properly attributed. For permission for commercial use of this work, please see paragraphs 4.2 and 5 of our Terms (https://www.dovepress.com/terms.php). 
Celecoxib, a nonsteroidal anti-inflammatory drug, has drawn much attention, due to its preventive role in many cancers, including colon, prostate, and breast cancers. ${ }^{8,9}$ In the development of CSCC, UV radiation is the main factor and causes skin-cell damage associated with Cox 2 and prostaglandins, which can be inhibited by these nonsteroidal antiinflammatory drugs. ${ }^{10,11}$ However, there have been no consistent conclusions in epidemiological studies or clinical research on the relationships between celecoxib and CSCC, especially the mechanisms by which celecoxib affects metastatic CSCC.

To investigate the association between celecoxib and CSCC further, we performed a series of studies in human samples and in vitro models to assess the influence of celecoxib in CSCC-cell migration. Moreover, we identified the mechanisms and intracellular signaling cascade underlying the protective role of celecoxib in CSCC. Herein, our results indicate that celecoxib suppresses CSCC-cell migration via inhibition of SDF1-induced endocytosis of CXCR4. In addition, ERK-Akt signaling pathways play a key role in this biological process. Our study provides promising evidence that celecoxib could be a potential preventive agent in the metastasis of CSCC cells.

\section{Materials and methods}

\section{Chemicals and antibodies}

MDC, AMD3100, celecoxib, and an anti-CXCR4 antibody were purchased from Sigma-Aldrich (St Louis, MO, USA). Additional antibodies used in these experiments included antiSDF1 (1:1,000,\#3530), anti-pAkt Ser473 (1:1,000, \#4060), anti-Akt (1:1,000,\#9272), and anti- $\beta$-actin (1:5,000,\#3700) from Cell Signaling Technology (Danvers, MA, USA). AntipERK1/2 (1:250) antibody was purchased from Santa Cruz Biotechnology (Dallas, TX, USA). Recombinant human SDF1 was purchased from Sigma-Aldrich and reconstituted to $100 \mu \mathrm{g} / \mathrm{mL}$ in sterile PBS containing $0.1 \%$ BSA.

\section{Immunohistochemistry}

Normal human-tissue and cancer-tissue sections were obtained from the Department of Dermatology at the First Affiliated Hospital of Fujian Medical University with institutional review board approval. Immunohistochemical staining was performed as described previously. ${ }^{12}$

\section{Cell culture and cell-viability assay}

The CSCC cell lines A431 and SCL1 were purchased from the American Type Culture Collection (Manassas, VA, USA) and cultured in DMEM (Thermo Fisher Scientific, Waltham, MA, USA) with 10\% FBS (Thermo Fisher Scientific) and $1 \%$ penicillin-streptomycin-glutamine (Thermo Fisher
Scientific) in a humidified incubator with $5 \% \mathrm{CO}_{2}$ atmosphere at $37^{\circ} \mathrm{C}$. Cytotoxicity of celecoxib was tested by Cell Counting Kit-8 (CCK8) assay. In brief, A431 cells $\left(2 \times 10^{5} /\right.$ well) were plated in each well of a 96-well plate with $100 \mu \mathrm{L}$ medium. After culture with different concentrations of celecoxib for 12 hours, cell viability was assessed using CCK8 according to the manufacturer's instructions. UV-radiation procedures have been described previously. ${ }^{13,14}$

\section{Western blotting}

Methods have been described previously. ${ }^{15-17}$ In brief, after each treatment, whole-cell lysates were prepared by sonication in Cellytic MT buffer (Sigma-Aldrich) with protease/phosphatase inhibitors (Cell Signaling Technology) and cleared by centrifugation. Samples consisting of $40 \mu \mathrm{g}$ proteins were resolved on a denaturing 4\%-20\% SDS-PAGE gel (Bio-Rad) and transferred to polyvinylidene fluoride membranes by electroblotting. Membranes were then blocked in PBS blocking buffer (Li-Cor) for 1 hour and incubated with specific primary antibodies at $4^{\circ} \mathrm{C}$ overnight. Blots were then incubated with species-specific secondary antibodies (Cell Signaling Technology). Signals were detected by a chemiluminescence reagent and analyzed with ImageJ software.

\section{Quantitative real-time PCR}

Cells were collected and total RNA extracted from $10^{7}$ cells using Trizol (Thermo Fisher Scientific) and treatment with an RNeasy clean-up kit (Qiagen, Venlo, the Netherlands) according to the manufacture's protocol. Total RNA was then reversetranscribed and the resulting cDNA quantified via quantitative real-time (qRT) PCR with SYBR green (Thermo Fisher Scientific). qRT-PCR results were calculated and normalized to GAPDH, an internal control, using the $\Delta \Delta \mathrm{Ct}$ method.

\section{Chemotaxis assay}

A431 cells were harvested, washed with PBS twice, and resuspended in FBS-free DMEM. Prepared cells $\left(10^{5} / 200 \mu \mathrm{L} /\right.$ well $)$ were plated in the upper chambers of transwell inserts $(8 \mu \mathrm{m}$ pores; Corning) and the lower chambers filled with different treatment solutions. Following a 12-hour incubation period, inserts were removed from the plate. Cells that had migrated were stained with Hema 3 fixative and solutions according to the manufacturer's instructions (Thermo Fisher Scientific). Adherent cells were then counted under microscopy.

\section{Enzyme-linked immunosorbent assay}

After different treatments, supernatants were centrifuged and collected. SDF1 levels in culture supernatants were measured 
with an SDF1 ELISA kit (Thermo Fisher Scientific) according to the manufacturer's instructions. Optical absorbance was measured at $450 \mathrm{~nm}$ in a multimode microplate reader (BioTek) at room temperature. SDF1 levels were calculated using the standard curve from the experiment.

\section{Endocytosis assay of chemokine receptor CXCR4}

In a kinetic assay of cell-surface expression of CXCR4, A431 cells were collected at different time points, where the reaction was stopped with an ice-cold PBS wash. To assess receptor endocytosis, cells were stained with the CXCR4 antibody and analyzed with flow cytometry (FACSCalibur; BD Biosciences, Franklin Lakes, NJ, USA) using CellQuest software.

\section{Statistical analysis}

All results were analyzed using unpaired Student's $t$-tests and expressed as mean \pm SEM of at least three separate experiments. $P$-values shown in figure legends or graphs were calculated using Prism 7.0 software (GraphPad Software, La Jolla, CA, USA).

\section{Results \\ SDFI expression upregulated in human CSCC, and UV radiation stimulated SDFI release and increased SDFI expression in CSCC cells}

$\mathrm{SDF} 1$ is known as a key regulator in cancer-cell migration. To assess SDF1 expression in CSCC, we performed immunohistochemistry on normal human skin and CSCC samples. We found that SDF1 expression was significantly upregulated in CSCC samples (Figure 1A). To determine whether UV radiation altered SDF1 release and expression in CSCC cells, SCL1 and A431 cells were challenged with UVB at different intensities $\left(0,3,5,10,20\right.$, and $\left.30 \mathrm{~mJ} / \mathrm{cm}^{2}\right)$ and subjected to quantitative analyses. Western blot analysis revealed that protein levels of SDF1 were robustly increased by UVB radiation in CSCC cells in a dose-dependent manner (Figure 1B and C). To verify SDF1 release by UVB radiation further, concentrated supernatant from cells after UVB radiation $\left(10,20\right.$, and $\left.30 \mathrm{~mJ} / \mathrm{cm}^{2}\right)$ was collected and SDF1 content examined by ELISA. These results demonstrated that UVB radiation promoted the release of SDF1 (Figure 1D and E). Subsequent analysis by qRT-PCR in both cell lines showed that UVB radiation led to an increase in SDF1 expression (Figure $1 \mathrm{~F}$ and $\mathrm{G}$ ). Taken together, these results show that UV radiation alters SDF1 release and increases the expression of SDF1 in CSCC cells.

\section{SDFI-induced cell migration in CSCC cells mediated by CXCR4 endocytosis}

To define the effect of SDF1 in CSCC-cell migration and its underlying mechanism further, cell migration was examined by chemotaxis assay in response to SDF1 with/without MDC or AMD3100. As expected, SDF1 largely induced CSCC-cell migration in a dose-dependent manner (Figure 2A and B). $\mathrm{MDC}$, an endocytosis inhibitor, significantly attenuated the cell migration induced by SDF1 (Figure 2A and C). Similar results were found in the group with cotreatment of AMD310, a CXCR4 inhibitor (Figure 2A and D). In addition, we examined the effect of CCX771, a specific inhibitor of CXCR7, on cell migration induced by SDF1, but did not observe a significant difference when compared to the control group (data not shown). To verify whether SDF1 affected endocytosis of CXCR4 in CSCC cells further, we challenged A431 cells with SDF1 at different doses and assessed CXCR4 expression on the plasma membrane. SDF1 notably induced CXCR4 endocytosis in CSCC cells in a dosedependent manner (Figure $3 \mathrm{~A}$ and $\mathrm{B}$ ). These results suggest that CXCR4 endocytosis is the key regulator in CSCC-cell migration induced by SDF1.

\section{Celecoxib abrogated SDFI-induced CSCC-cell migration by CXCR4- endocytosis inhibition}

SDF1 was observed to increase CSCC-cell migration via CXCR4 endocytosis. We first tested the effect of celecoxib on CSCC-cell viability. CCK8-assay results demonstrated that celecoxib did not affect the viability of CSCC cells in 12 hours (Figure 2F). To address the relative role of celecoxib in this process further, we challenged A431 cells with SDF1 at different doses with celecoxib. Celecoxib robustly abrogated the CSCC-cell migration induced by SDF1 (Figure 2A and $\mathrm{E})$. In addition, we observed that $\mathrm{CXCR} 4$ endocytosis was suppressed by cotreatment with celecoxib, indicating the inhibitory influence of celecoxib on SDF1-induced endocytosis of CXCR4 (Figure 3C and D).

\section{Celecoxib inhibited SDFI-induced endocytosis of CXCR4 via ERK-Akt signaling pathways in CSCC cells}

Our aforementioned results demonstrated that SDF1induced CSCC-cell migration was regulated by CXCR4 endocytosis. In addition, recent studies have implicated ERK- and Akt-signaling pathways as key factors in cancercell migration. ${ }^{18,19}$ To delineate underlying mechanisms and signaling pathways mediating SDF1-induced cell 
A

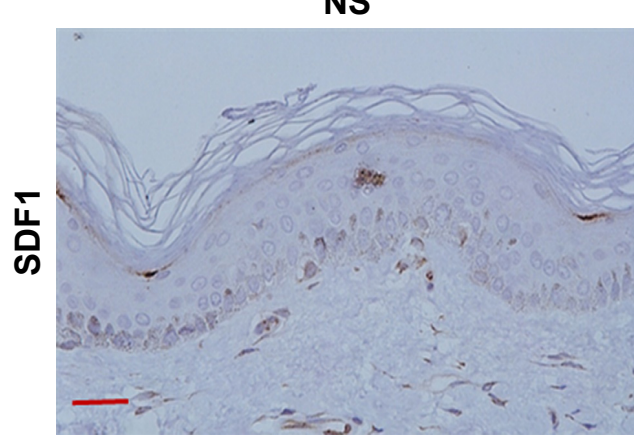

B

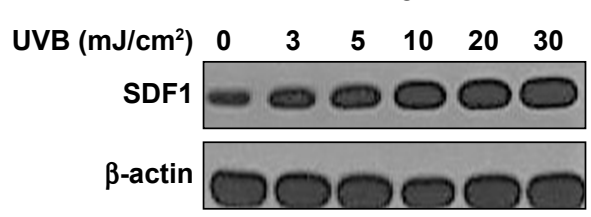

D
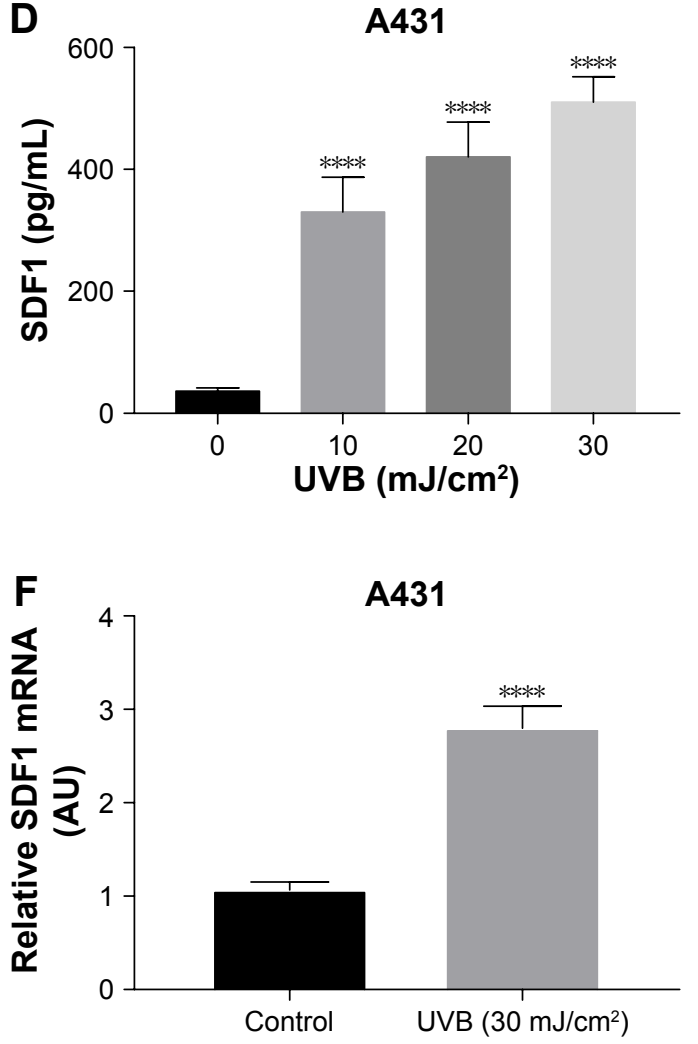

$\operatorname{cscc}$

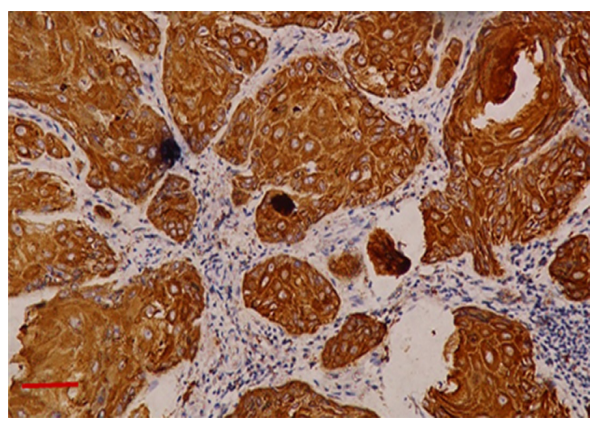

C

SCL1
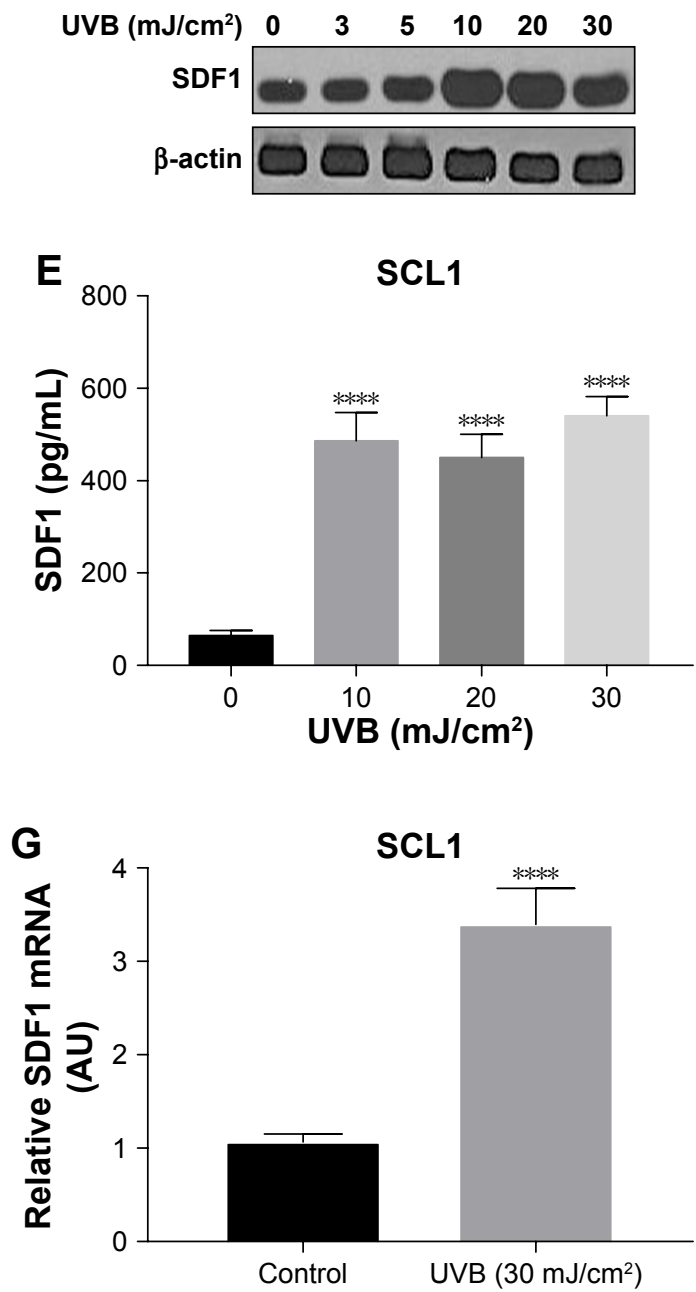

Figure I Ultraviolet (UV) radiation induced SDFI secretion and increased the expression of SDFI in cutaneous squamous-cell carcinoma (CSCC) cells. Notes: (A) Immunohistochemical analysis of SDFI in normal skin (NS) and CSCC samples ( $=5$ ). CSCC cell lines (A43I and SCLI) were exposed to UV radiation at indicated doses and cultured in complete medium for an additional 12 hours (Magnification: $\times 40$; scale bar: $100 \mu$ m). Cell lysates (B, C) and supernatants (D, E) were collected and subjected to Western blot analysis and ELISA for SDFI expression and release, respectively. mRNA levels of SDFI (F, G) were assessed by reverse-transcription PCR. Results expressed as mean \pm SEM of three independent experiments. ***** $P<0.0001$ compared to control groups by unpaired Student's $t$-tests.

migration further, we examined whether SDF1 induced cell migration via ERK-Akt pathways. A431 and SCL1 cells were pretreated with MDC, a CXCR4-neutralizing antibody, or AMD3100 prior to SDF1 challenge. After treatment, cells were collected and subjected to Western blot analysis. Upon treatment of SDF1, both ERK and Akt pathways were activated. Moreover, this activation was abrogated in response to treatment with MDC, 


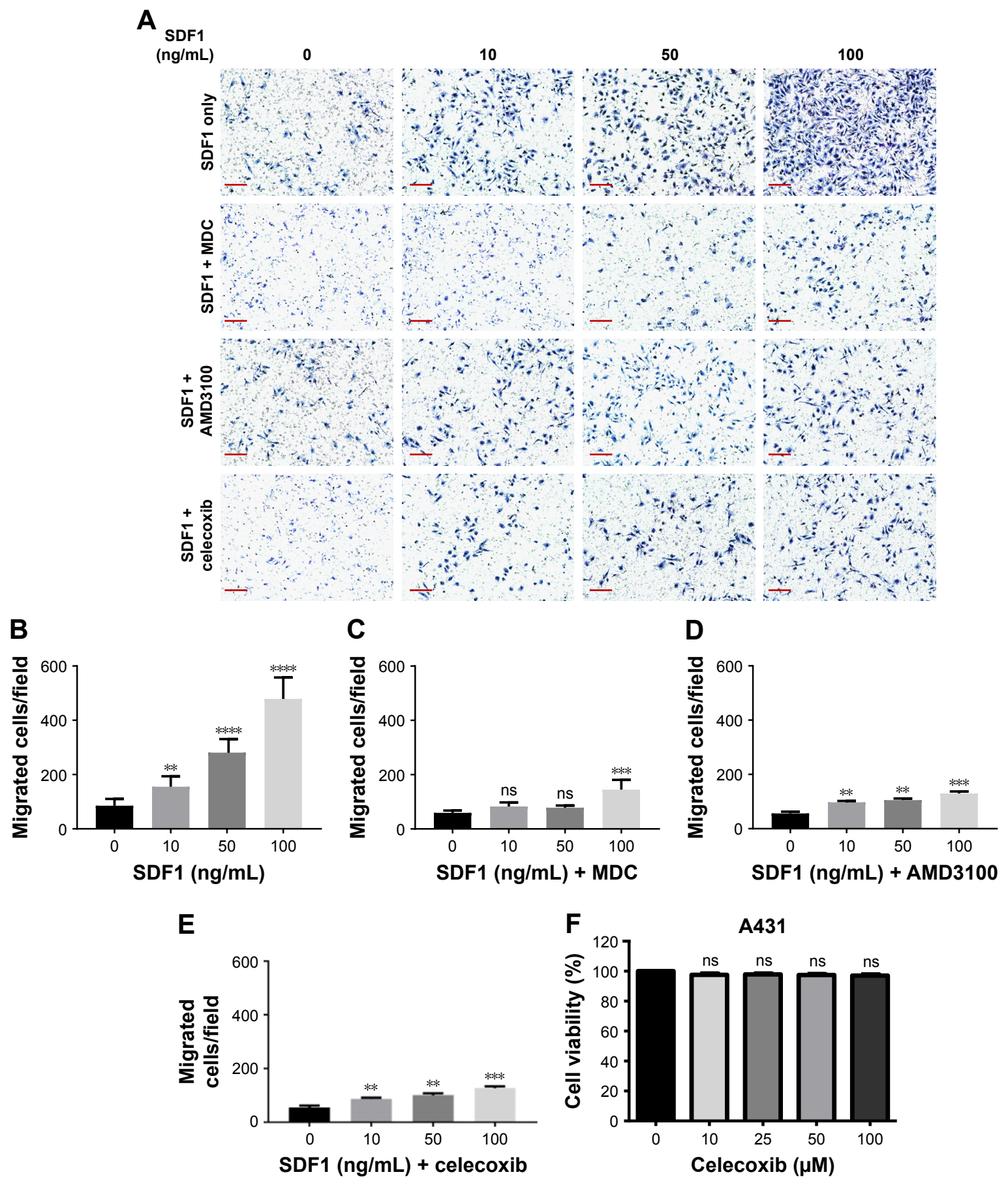

Figure 2 Celecoxib suppressed SDFI-induced cell migration in squamous-cell carcinoma (CSCC) cells.

Notes: CSCC cells (A43I) were pretreated with MDC (I0 $\mathrm{MM})$ or AMD3100 (I00 nM) for I hour prior to SDFI challenge at indicated doses for I2 hours. A43I cells were also challenged with SDFI at different doses with celecoxib (100 $\mu \mathrm{M})$. Cell migration was examined with Boyden assays. (A) Representative figures of migrated cells in each group at different conditions (Magnification: $\times 40$; scale bar: $100 \mu \mathrm{m}$ ). (B) Quantification of migrated cells showed that SDFI induced cell migration in a dose-dependent manner. MDC, AMD3100, and celecoxib (C-E) abrogated the effect of SDFI in CSCC-cell migration. (F) Effects of celecoxib on the viability of A43I cells. A43I cells were treated with different concentrations of celecoxib as indicated, and cell viability was measured with CCK8 assays after 12 hour. Results expressed as mean \pm SEM/microscopic field $(\mathrm{n}=3) . * * P<0.01, * * * P<0.001, * * * * P<0.0001$ compared to SDFI groups by unpaired Student's $t$-tests.

Abbreviation: ns, not significant.

CXCR4-neutralizing antibody, or AMD3100 (Figure 4A and B). CSCC cells were also treated with SDF1 in the presence or absence of celecoxib for 24 hours. Similar effects were observed when cells were cotreated with celecoxib (Figure 4C and D). These results revealed that ERK-Akt pathways played a critical role in the inhibitory effect of celecoxib in SDF1-induced CSCC-cell migration and CXCR4 endocytosis. 
A

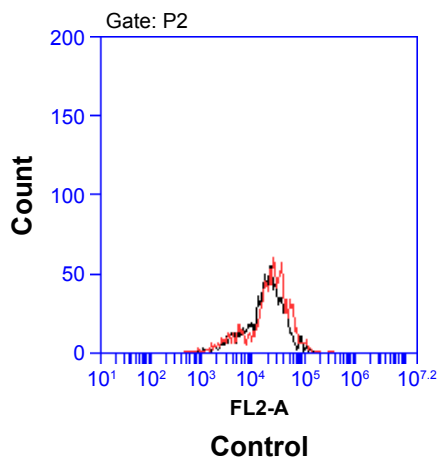

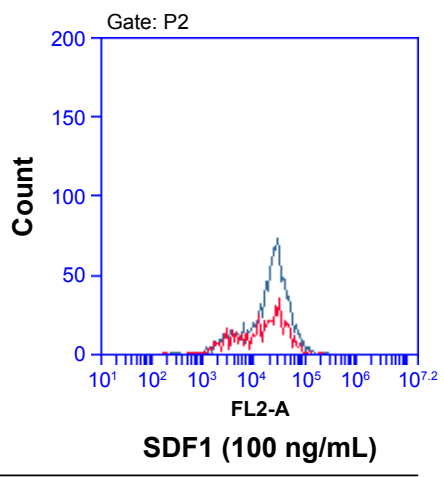

1 minute
B

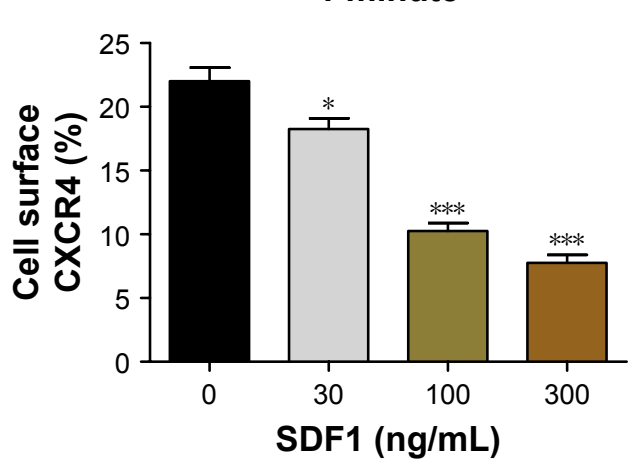

D

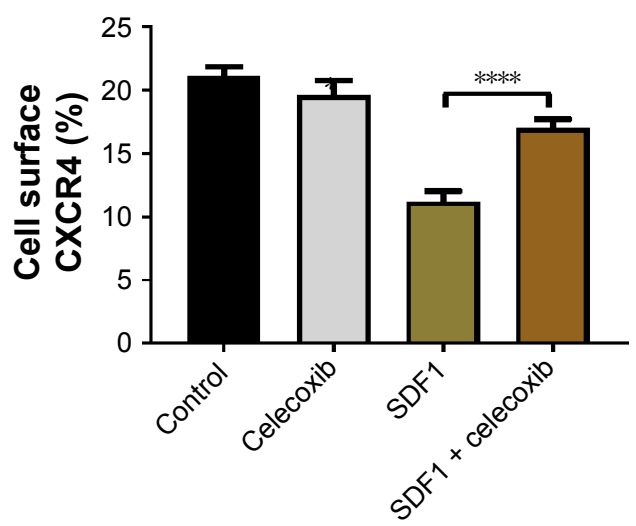

Figure 3 Celecoxib repressed SDFI-induced endocytosis of CXCR4 in cutaneous squamous-cell carcinoma (CSCC) cells.

Notes: CSCC cells (A43I) were challenged with SDFI at different doses with or without celecoxib (100 $\mu$ M) and expression of CXCR4 on plasma membrane was determined by flow cytometry. (A) Representative images of flow-cytometry analysis show that SDFI induced CXCR4 endocytosis in CSCC cells after I minute. (B) SDFI induced CXCR4 endocytosis in a dose-dependent manner. (C) Data represent percentage of CXCR4 expression on plasma membrane under different treatments. (D) Celecoxib repressed SDFI-induced reduction of CXCR4 in CSCC cells. Results expressed as mean $\pm \mathrm{SEM}$ of three independent experiments. $* P<0.05$, $* * * P<0.00 \mathrm{I}$, $* * * * P<0.000 \mathrm{I}$ compared to control group by unpaired Student's $t$-tests.

\section{Discussion}

Most fatalities caused by CSCC are related to its local recurrence and metastatic characteristics. ${ }^{20}$ Much effort has been devoted to identifying novel chemicals that may help protect against and prevent CSCC metastasis. The present study aimed to investigate whether celecoxib is a potential preventive agent of metastasis in CSCC cells and to identify the underlying mechanisms.

SDF1 is well known for its biological actions in cell migration, proliferation, and survival in a variety of cancers, including hepatocellular carcinoma and prostate cancer. ${ }^{21,22}$ CXCR4, a chemokine receptor of SDF1, is overexpressed in several cancers and plays an important role in cell migration and tumor metastasis. ${ }^{23}$ The SDF1-CXCR4 axis has been reported to regulate the migration and localization of melanoblasts in mouse hair follicles. ${ }^{24,25}$ Our present study found that SDF1 expression was significantly upregulated in human CSCC and UV radiation induced a robust secretion of SDF1 in CSCC cells and also elevated protein levels of SDF1 in these cells. In addition, the effects of UV-induced SDF1 on the migration of CSCC cells were examined. Results demonstrated that migrated cells were significantly increased when treated with SDF1, and this effect was largely attenuated by treatment with a CXCR4 inhibitor and endocytosis inhibitor. Most importantly, celecoxib inhibited the cell migration induced by SDF1 via suppression of the endocytosis of CXCR4 in CSCC cells.

Celecoxib, a nonsteroidal anti-inflammatory Cox2 inhibitor, has been indicated in a phase II trial potentially to reduce the number of tumors in certain skin cancers. ${ }^{26}$ However, the clinical therapy of celecoxib for skin cancer is limited by concerns about adverse events observed in the gastrointestinal system, cardiovascular system, kidneys, and liver. ${ }^{27-29} \mathrm{COX} 2$ is the main enzyme critical in the conversion of arachidonic acid to $\mathrm{PGE}_{2}$, which regulates the production of many inflammatory cytokines. However, the effect of 
A

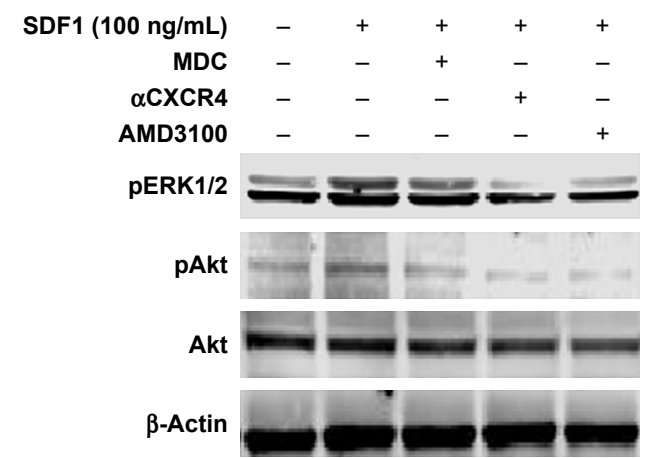

B

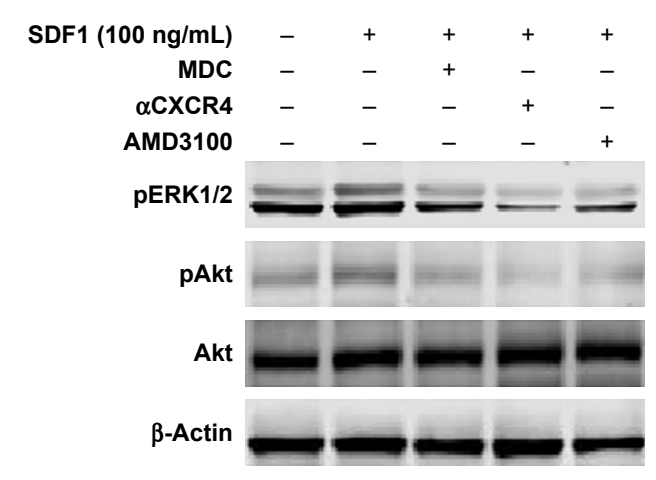

C

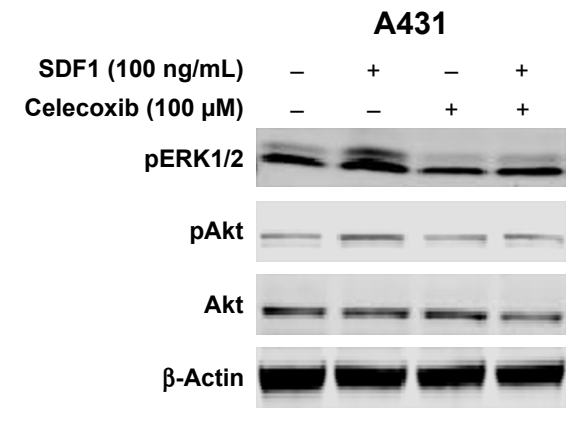

D

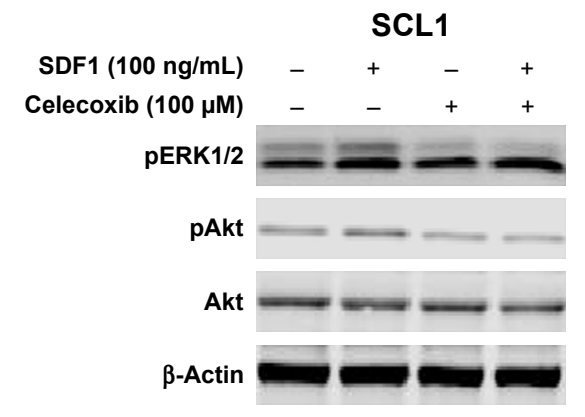

A431

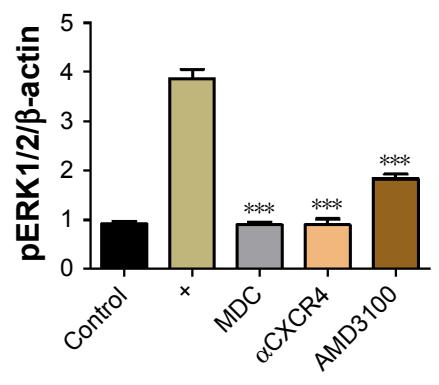

SDF1 (100 ng/mL)

SCL1

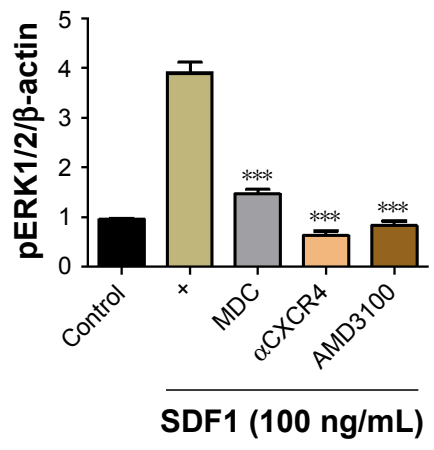

A431

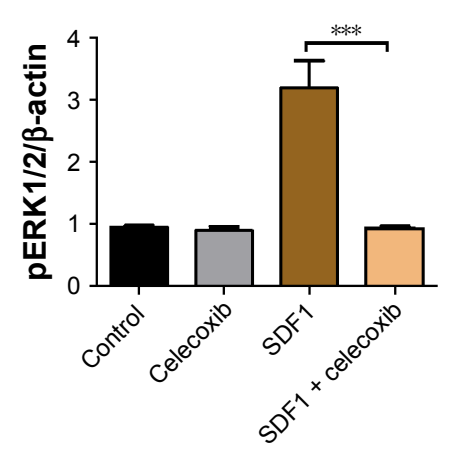

SCL1

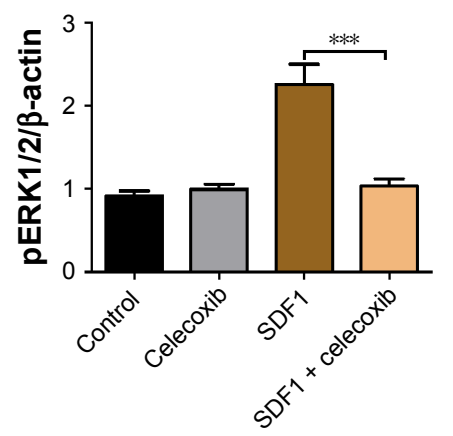

A431

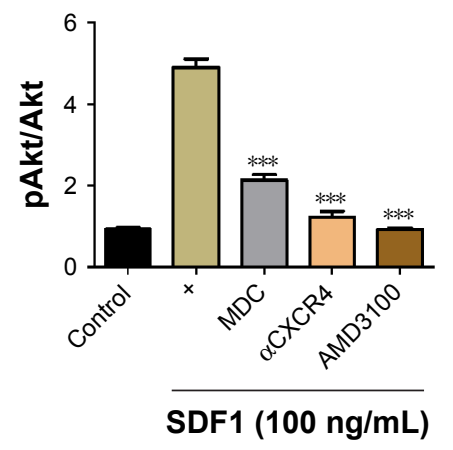

SCL1

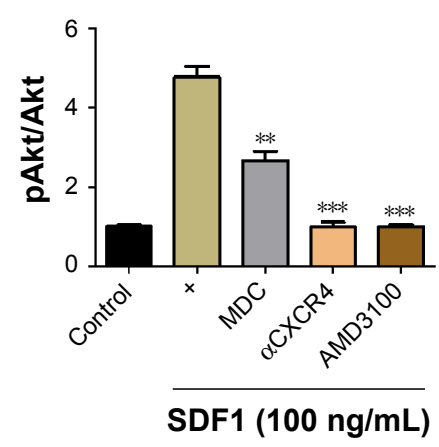

A431

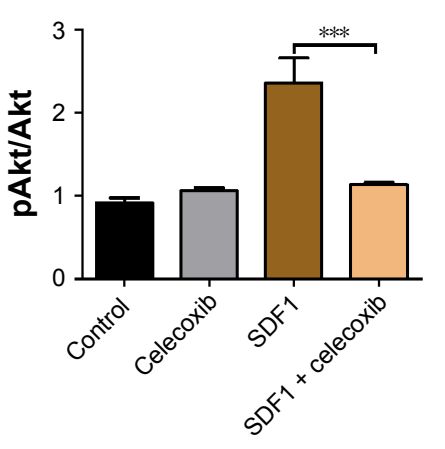

SCL1

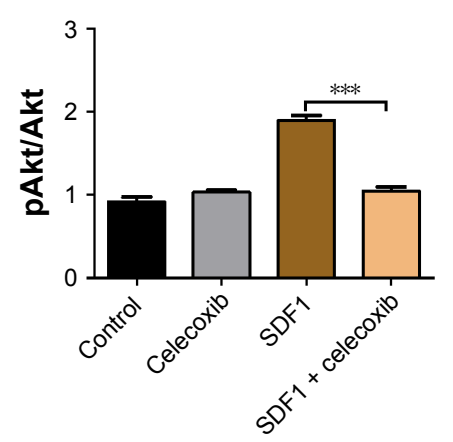

Figure 4 Celecoxib inhibited SDFI-induced activation of Akt-ERK signaling pathways.

Notes: Cutaneous squamous-cell carcinoma (CSCC) cells (A43I and SCLI) were pretreated with MDC (I0 $\mu M$ ), CXCR4-neutralizing antibody, or AMD3I00 $(100 \mathrm{nM})$ for I hour prior to SDFI $(100 \mathrm{ng} / \mathrm{mL})$ challenge for 24 hours. At the end of treatment, activation of pERK, pAkt, Akt, and $\beta$-actin was analyzed by Western blot (A, B). CSCC cells (A43I and SCLI) were treated with SDFI ( $100 \mathrm{ng} / \mathrm{mL}$ ) with or without celecoxib (I00 $\mu \mathrm{M})$ for 24 hours (C, D). Levels of pERK and pAkt were quantified and normalized to $\beta$-actin and Akt, respectively. Results shown as mean \pm SEM of three independent experiments. $* * P<0.01$, $* * * P<0.001$ compared to SDFI group by unpaired Student's $t$-tests. 


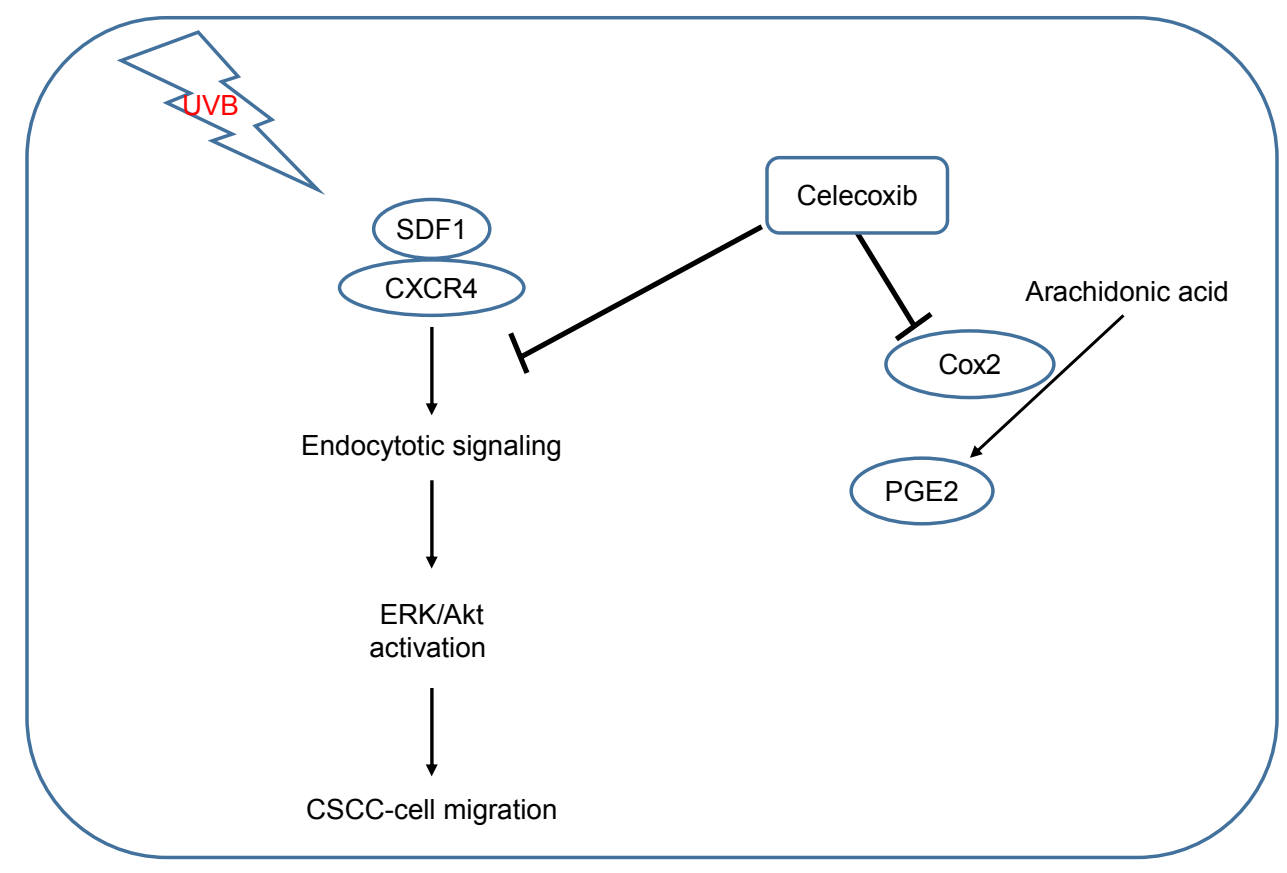

Figure 5 Schematic model of the proposed mechanism.

Note: Celecoxib inhibits CSCC-cell migration via suppression of SDFI/CXCR4-mediated ERK/Akt activation.

Abbreviations: CSCC, cutaneous squamous-cell carcinoma; UVB, ultraviolet B.

celecoxib in metastatic CSCCs and the mechanisms underlying this effect remain poorly understood. Herein, we tested the relevance of celecoxib in the regulation of SDF1-induced cell migration and endocytosis of CXCR4. Moreover, we demonstrated that SDF1-induced cell migration of CSCC cells was mediated by the activation of ERK-Akt pathways, which was largely attenuated by cotreatment with celecoxib. These findings are in accordance with the fact that the ERKsignaling pathway is essential in cell proliferation, cell survival, and cell migration. ${ }^{30-33}$

In conclusion, our results show that SDF1 is notably upregulated in human CSCC and that UV radiation increases the secretion and protein levels of SDF1 in CSCC cells. Additionally, celecoxib attenuates SDF1-induced cell migration of CSCC cells by inhibiting endocytosis of CXCR4 via ERK-Akt signaling pathways (Figure 5). Here, we have uncovered a crucial role of celecoxib in cell migration in CSCC, suggesting its potential value as a novel therapeutic of CSCC.

\section{Acknowledgment}

This research was supported by grants from the National Natural Science Foundation of China (81673066 and 81473684), the Natural Science Foundation of Fujian Province (2016J01534), and Joint Funds for the Innovation of Science and Technology of Fujian province (2016Y91020018).

\section{Author contributions}

$\mathrm{CJ}$ and $\mathrm{BC}$ designed the experiments, wrote the manuscript, and provided materials, TG, YY, JWH, and ML performed experiments and analyzed the data, and BY provided analysis tools. All authors contributed to data analysis, drafting and revising the article, gave final approval of the version to be published, and agree to be accountable for all aspects of the work.

\section{Disclosure}

The authors report no conflicts of interest in this work.

\section{References}

1. Rogers HW, Weinstock MA, Harris AR, et al. Incidence estimate of nonmelanoma skin cancer in the United States, 2006. Arch Dermatol. 2010;146(3):283-287.

2. Brantsch KD, Meisner C, Schönfisch B, et al. Analysis of risk factors determining prognosis of cutaneous squamous-cell carcinoma: a prospective study. Lancet Oncol. 2008;9(8):713-720.

3. Czarnecki D, Staples M, Mar A, Giles G, Meehan C. Metastases from squamous cell carcinoma of the skin in southern Australia. Dermatology. 1994;189(1):52-54.

4. Baggiolini M. Chemokines in pathology and medicine. J Intern Med. 2001;250(2):91-104.

5. Pelekanos RA, Ting MJ, Sardesai VS, et al. Intracellular trafficking and endocytosis of CXCR4 in fetal mesenchymal stem/stromal cells. BMC Cell Biol. 2014;15:15.

6. Signoret N, Oldridge J, Pelchen-Matthews A, et al. Phorbol esters and SDF-1 induce rapid endocytosis and down modulation of the chemokine receptor CXCR4. J Cell Biol. 1997;139(3):651-664. 
7. Amara A, Gall SL, Schwartz O, et al. HIV coreceptor downregulation as antiviral principle: SDF-1alpha-dependent internalization of the chemokine receptor CXCR4 contributes to inhibition of HIV replication. J Exp Med. 1997;186(1):139-146.

8. Williams CS, Watson AJ, Sheng H, Helou R, Shao J, Dubois RN. Celecoxib prevents tumor growth in vivo without toxicity to normal gut: lack of correlation between in vitro and in vivo models. Cancer Res. 2000; 60(21):6045-6051.

9. van Wijngaarden J, van Beek E, van Rossum G, et al. Celecoxib enhances doxorubicin-induced cytotoxicity in MDA-MB231 cells by NF-kappaB-mediated increase of intracellular doxorubicin accumulation. Eur J Cancer. 2007;43(2):433-442.

10. Fecker LF, Stockfleth E, Nindl I, Ulrich C, Forschner T, Eberle J. The role of apoptosis in therapy and prophylaxis of epithelial tumours by nonsteroidal anti-inflammatory drugs (NSAIDs). Br J Dermatol. 2007; 156 Suppl 3:25-33.

11. Rundhaug JE, Simper MS, Surh I, Fischer SM. The role of the EP receptors for prostaglandin E2 in skin and skin cancer. Cancer Metastasis Rev. 2011;30(3-4):465-480.

12. Ji C, Zhang Y, Heller P, Guo Y. Melanocytic Matrical Carcinoma Mimicking Melanoma. Am J Dermatopathol. 2017;39(12):903-906.

13. Ji C, Yang YL, Yang Z, et al. Perifosine sensitizes UVB-induced apoptosis in skin cells: new implication of skin cancer prevention? Cell Signal. 2012;24(9):1781-1789.

14. Yang B, Ji C, Kang J, Chen W, Bi Z, Wan Y. Trans-Zeatin inhibits UVBinduced matrix metalloproteinase-1 expression via MAP kinase signaling in human skin fibroblasts. Int J Mol Med. 2009;23(4):555-560.

15. Ji C, Yang B, Huang SY, Huang JW, Cheng B. Salubrinal protects human skin fibroblasts against UVB-induced cell death by blocking endoplasmic reticulum (ER) stress and regulating calcium homeostasis. Biochem Biophys Res Commun. 2017;493(4):1371-1376.

16. Ji C, Zhang Z, Chen L, et al. Endoplasmic reticulum stress-induced autophagy determines the susceptibility of melanoma cells to dabrafenib. Drug Des Devel Ther. 2016;10:2491-2498.

17. Yang B, Xu QY, Guo CY, et al. MHY1485 ameliorates UV-induced skin cell damages via activating mTOR-Nrf2 signaling. Oncotarget. 2017;8(8):12775-12783.

18. Huo YN, Chen W, Zheng XX. ROS, MAPK/ERK and PKC play distinct roles in EGF-stimulated human corneal cell proliferation and migration. Cell Mol Biol. 2015;61(7):6-11.

19. Henderson V, Smith B, Burton LJ, Randle D, Morris M, Odero-Marah VA. Snail promotes cell migration through PI3K/Akt-dependent Rac1 activation as well as PI3K/Akt-independent pathways during prostate cancer progression. Cell Adh Migr. 2015;9(4):255-264.

20. Uribe P, Gonzalez S. Epidermal growth factor receptor (EGFR) and squamous cell carcinoma of the skin: molecular bases for EGFRtargeted therapy. Pathol Res Pract. 2011;207(6):337-342.
21. García-Irigoyen O, Latasa MU, Carotti S, et al. Matrix metalloproteinase 10 contributes to hepatocarcinogenesis in a novel crosstalk with the stromal derived factor $1 / \mathrm{C}-\mathrm{X}-\mathrm{C}$ chemokine receptor 4 axis. Hepatology. 2015;62(1):166-178.

22. Gravina GL, Mancini A, Muzi P, et al. CXCR4 pharmacogical inhibition reduces bone and soft tissue metastatic burden by affecting tumor growth and tumorigenic potential in prostate cancer preclinical models. Prostate. 2015;75(12):1227-1246.

23. Xu C, Zhao H, Chen H, Yao Q. CXCR4 in breast cancer: oncogenic role and therapeutic targeting. Drug Des Devel Ther. 2015;9:4953-4964.

24. Belmadani A, Jung H, Ren D, Miller RJ. The chemokine SDF-1/ CXCL12 regulates the migration of melanocyte progenitors in mouse hair follicles. Differentiation. 2009;77(4):395-411.

25. Quan C, Cho MK, Shao Y, et al. Dermal fibroblast expression of stromal cell-derived factor-1 (SDF-1) promotes epidermal keratinocyte proliferation in normal and diseased skin. Protein Cell. 2015;6(12):890-903.

26. Celecoxib may decrease some skin cancers. Nurse Pract. 2010; $35(6): 17$.

27. Mcgettigan P, Henry D. Cardiovascular risk with non-steroidal antiinflammatory drugs: systematic review of population-based controlled observational studies. PLoS Med. 2011;8(9):e1001098.

28. Whelton A, Maurath CJ, Verburg KM, Geis GS. Renal safety and tolerability of celecoxib, a novel cyclooxygenase-2 inhibitor. Am J Ther. 2000;7(3):159-174.

29. Soni P, Shell B, Cawkwell G, Li C, Ma H. The hepatic safety and tolerability of the cyclooxygenase-2 selective NSAID celecoxib: pooled analysis of 41 randomized controlled trials. Curr Med Res Opin. 2009; 25(8):1841-1851.

30. Huang C, Jacobson K, Schaller MD. MAP kinases and cell migration. $J$ Cell Sci. 2004;117(Pt 20):4619-4628.

31. Bove PF, Hristova M, Wesley UV, Olson N, Lounsbury KM, van der Vliet A. Inflammatory levels of nitric oxide inhibit airway epithelial cell migration by inhibition of the kinase ERK $1 / 2$ and activation of hypoxiainducible factor-1 alpha. J Biol Chem. 2008;283(26):17919-17928

32. Kim J, Ahn S, Rajagopal K, Lefkowitz RJ. Independent beta-arrestin2 and $\mathrm{Gq}$ /protein kinase Czeta pathways for ERK stimulated by angiotensin type $1 \mathrm{~A}$ receptors in vascular smooth muscle cells converge on transactivation of the epidermal growth factor receptor. J Biol Chem. 2009;284(18):11953-11962.

33. Pierce KL, Maudsley S, Daaka Y, Luttrell LM, Lefkowitz RJ. Role of endocytosis in the activation of the extracellular signal-regulated kinase cascade by sequestering and nonsequestering $\mathrm{G}$ protein-coupled receptors. Proc Natl Acad Sci U S A. 2000;97(4):1489-1494.
OncoTargets and Therapy

\section{Publish your work in this journal}

OncoTargets and Therapy is an international, peer-reviewed, open access journal focusing on the pathological basis of all cancers, potential targets for therapy and treatment protocols employed to improve the management of cancer patients. The journal also focuses on the impact of management programs and new therapeutic agents and protocols on

\section{Dovepress}

patient perspectives such as quality of life, adherence and satisfaction. The manuscript management system is completely online and includes a very quick and fair peer-review system, which is all easy to use. Visit http://www.dovepress.com/testimonials.php to read real quotes from published authors. 